\title{
CANDIDO EM ANGOLA: DUAS FORMAÇÕES CANDIDO IN ANGOLA: TWO FORMAÇÕES
}

\author{
Francisco Manoel Antunes'
}

RESUMO: Este breve ensaio visa comparar as obras Formação da literatura brasileira, de Antonio Candido, e A formação da literatura angolana, de Mário António (Angola). A conclusão evidente é a de que o primeiro serviu de modelo metodológico para o segundo. A hipótese menos evidente é a de que essa coincidência revela, não só a influência de Candido em um país onde não tem sido estudada, mas também a fidelidade de $M$. António à sua formação inicial, comum à dos companheiros da Mensagem de Luanda.

PALAVRAS-CHAVE: história literária, sistema literário, Angola, Brasil.

ABSTRACT: This brief essay aims to compare the books Formação da Literatura Brasileira, by Antonio Candido, and $A$ Formação da literatura angolana, by Mário António (Angola). The obvious conclusion is that the former served as a methodological model for the latter. The less obvious hypothesis is that this coincidence reveals not only the influence of Candido in a country where it has not been studied but also the fidelity of M. António to his initial formation, common to that of the companions of Message (Luanda).

KEYWORDS: literary history, literary system, Angola, Brazil.

1 Investigador integrado no Centro de Investigação Transdisciplinar «Cultura, Espaço e Memória» da Faculdade de Letras da Universidade do Porto. Professor Associado com Agregação pela Universidade de Évora e Professor Titular da Universidade Agostinho Neto. 


\section{Introdução}

Mário António Fernandes de Oliveira tem sido analisado e criticado em razão de disputas político-partidárias e de lutas pelo poder cultural e simbólico. Ele próprio foi vítima e protagonista delas ao tentar sobreviver entre as duas tenazes do colonialismo português e do nacionalismo ideológico (o restante ele raramente leva em conta). O condicionamento político-partidário é tal que, ao nos envolvermos com a interpretação da sua obra, somos imediatamente conotados com qualquer grupo de poder, ou qualquer intenção de poder, reduzindo a ela o que dizemos - tanto quanto se fez com os seus livros e artigos.

Em contraposição, tenta-se compreender aquela pessoa na sua obra e, por outro lado, verificar a pertinência das leituras e dos conceitos que usou. Como parte desse projeto de compreensão, neste momento, o que se vai fazer é testar uma hipótese ainda não explorada, a de que ele se manteve estruturalmente fiel à formação inicial, discordando dos rumos tomados pelo nacionalismo angolano e da leitura negritudinista da respetiva realidade cultural sem, no entanto, abandonar uma interpretação da literatura atenta aos aspetos artísticos mas, ao mesmo tempo, interpretando-a pelas articulações com as forças históricas e sociais envolventes. Nisso, não divergiu dos seus amigos da Mensagem. Livre que estava de uma leitura resumida ao confronto negro-branco, ou condicionada pela hipótese da incomunicabilidade na relação colonizado-colonizador, divergiu nas conclusões a que a aplicação do método o levou, mas não divergiu, essencialmente, no método. É pela confrontação entre o seu trabalho e o de Antonio Candido que vamos perceber isso.

Muitas vezes, associado ao lusotropicalismo, ele próprio não o negou, embora por motivos circunstanciais. Havia, ligando-o a Gilberto Freyre, o reconhecimento da importância do estudo de como os portugueses estiveram nos trópicos para se conhecer as comunidades intermédias que se desenvolveram nas suas colónias. O reconhecimento, também, da presença da literatura portuguesa, e da literatura mundial a partir dela, para se compreender como se foi forjando localmente uma prática literária que, com lentidão notória, se foi aproximando cada vez mais da oralidade e da especificidade cultural envolvente dessas elites estrangeiradas - aliás, inicialmente estrangeiras. Muitas vezes acossado por assumir o caráter intermédio (e não necessariamente racial, muito menos étnico) das comunidades urbanas onde se forjou o nacionalismo moderno angolano, ele 
citaria Gilberto Freyre, não só pelas afinidades encontradas, mas mesmo para sublinhar a sua discordância face aos companheiros e chamar a discussão para esse campo. Não importa, para efeitos deste texto, se tinha razão - uma razão parcialmente concedida por Mário Pinto de Andrade ao filiar as Origens do nacionalismo africano, principalmente (e parcialmente), nas elites do século XIX para cuja importância Mário António chamava a atenção e nas quais estudava o processo de formação da literatura angolana. Ficaram por explicar, nesse livro de Mário Pinto de Andrade, as origens dos outros nacionalismos angolanos e africanos, que inicialmente se formaram entre elites regionais, autoidentificando-se pelas suas raízes etno-históricas, parcelares em relação ao território angolano e reunindo povos hoje divididos por fronteiras diversas - incluindo as partidárias e as nacionais. Tanto quanto nos ensaios de Mário António, também a formação da nação angolana foi vista por M. P. Andrade a partir dos núcleos urbanos, transétnicos, em que a defesa do novo grupo supera as divisões derivadas das pertenças a genealogias diferentes. Ou seja: ainda neste aspeto, os dois antigos companheiros se mantiveram fiéis à sua formação inicial em Luanda.

Mas a visão que estrutura os estudos de Mário António sobre como se foi formando uma literatura angolana é uma visão crioula, se preferirmos, uma visão na qual o processo de crioulização, ou hibridação, ou miscigenação cultural é o próprio motor da constituição de uma literatura que se propõe angolana. Com lucidez ele demonstra, pelos estudos sobre o século XIX e começos do seguinte, que o processo de constituição de uma literatura situada só vingou nesse meio híbrido. Foi esta visão crioula, descritiva, explicativa, mas nunca prescritiva, que se manteve até ao fim, quando as referências ao lusotropicalismo desapareceram. Torna-se, portanto, imprescindível, para considerar o contributo ensaístico do autor de Maquela, separar o que foi lusotropicalismo do que foi teoria da crioulidade. Justamente o segundo aspeto se manteve num livro que se torna fundamental para este ensaio e que resultou da sua tese de doutoramento, com a qual coroou uma carreira longa de pesquisa e de ensaio.

Mesmo levando em conta que a sua é uma visão que se pretende crioula, não podemos reduzir a tal visão os seus modelos e os métodos de análise, pois ela constitui perspetiva geral, enfoque, não tem cariz metodológico. Ele vai buscar métodos e modelos em autores cujas filiações e propostas entroncam seriamente no figurino intelectual da sua formação quando jovem liceal e cofundador do Partido Comunista Angolano. As acesas discussões em torno do conceito de 
crioulidade acabaram desconsiderando estes aspetos fundamentais do trabalho de Mário António. Um deles se prende, precisamente, com o tema deste número da Via Atlântica: Antonio Candido, referência também dos intelectuais de esquerda angolanos.

Ao apresentar a sua tese de doutoramento à Universidade Nova de Lisboa, Mário António deu-lhe por título $A$ formação da literatura angolana. Parece incrível que, desde então, não se tenha reparado bem nesse título. A semelhança com Formação da literatura brasileira, de Antonio Candido, é tão evidente que deve ter sido propositada. Seja como for, não se trata de mera coincidência, mas do sinal de outra leitura estruturante para o ensaísta angolano, que chegou a lecionar Literatura Brasileira, disciplina na qual foi professor, por exemplo, do crítico português Abel Barros Baptista². Mário António projetou, para a história da formação do sistema literário angolano, algo semelhante ao que fez Antonio Candido para compreendermos a gestação do sistema literário brasileiro. $\mathrm{O}$ meu contributo para este número da revista visa, precisamente, verificar isso.

\section{Significado do título}

Destaque-se, em primeiro lugar, a coincidência dos títulos, uma evidência ultrajada pelo silêncio. Mário António apenas acrescenta o artigo definido ("A"), o resto é igual. $O$ título propõe-nos também duas balizas cronológicas em ambos os casos. Antonio Candido põe, no "1.ㅇ volume", entre parêntesis, "1750-1836". Mário António põe “(1851-1950)".

O que há de comum nas respetivas comunidades literárias, nesses períodos, é fundamental: o momento em que se organizam e articulam os seus protagonistas, independentemente do grau de programação da rede textual, e se definem como escritores localizados numa região destacada e diferenciada do lugar de referência da literatura tutelar, no caso a portuguesa, como parcela da europeia.

2 A minha referência ao crítico português prende-se, não tanto com a polémica gerada pelo seu posfácio à antologia de textos de Antonio Candido publicada em Portugal, mas bem mais ao facto de Abel Barros Baptista ter sido aluno de Mário António em Literatura Brasileira e confessar, em entrevista a Adriano Schwartz para a Folha de São Paulo (SP, 16-1-2005, suplemento +mais; https://www1.folha.uol.com.br/fsp/mais/fs1601200506.htm), que "a minha aprendizagem da literatura brasileira fez-se em boa parte em diálogo com os estudos de Antonio Candido." 
O momento, portanto, em que, respeitando embora o cânone vigente na literatura que se tornava mundial, as comunidades literárias locais iniciaram o processo de diferenciação face à 'metrópole' europeia, começaram a cortar o cordão umbilical enquanto formavam uma rede textual própria, interligada e contínua. Ao mesmo tempo, os seus protagonistas políticos, por vezes coincidentes, esboçavam divergências em relação aos interesses metropolitanos e, por essas e outras vias, começaram a fermentar ideais de independência, de separação da mesma metrópole.

No Brasil o processo teve, segundo Antonio Candido, basicamente duas fases: a do Arcadismo e a do Romantismo. Em Angola, o começo do processo dá-se com a instalação da tipografia, finalmente permitida e, até, oficial. É provável que, havendo antes tipografias, antes houvesse também sinais da constituição, pelo menos da tendência para se constituir um sistema literário local. Entretanto, só a existência de um parque gráfico nos legou documentação suficiente para estudarmos o caso. Por isso é que, estudando Angola, constantemente se associa - como faz Mário António - a instalação do prelo e a formação do sistema literário local. Em Angola, também, houve duas fases bem diferenciadas: a que veio até ao início do século XX e a que foi daí até 1849. As duas estão, veremos agora isso, ligadas por fios de continuidade que a leitura de Mário António deteta, aplicando um método de trabalho que está bem exposto no livro de Antonio Candido, cerca de três décadas anterior ao seu.

\section{Passo a passo}

Sugiro que se coteje agora os dois livros. Não é necessário fazer a comparação seguindo a Formação da literatura brasileira do princípio ao fim. A consideração das épocas e dos protagonistas específicos, naturalmente, é a parte das obras em que elas mais divergem, porque os acontecimentos estão mais localizados que a visão geral ou metodológica do seu estudo. Para o efeito que se persegue neste ensaio, o que interessa é a definição do método e das hipóteses a ele associadas. Ora isso é feito, principalmente, nos prefácios a várias edições e no capítulo I. Antonio Candido se queixaria, de novo, de só se comentar essa parte, mas, para esta comparação, tem de ser mesmo assim. 
O ensaísta brasileiro, no prefácio à primeira edição, destaca o seu desprendimento relativamente à erudição. Face ao esquadrinhamento exaustivo, Candido prefere o predomínio do juízo crítico orientado pelo gosto e a preocupação em interpretar esse momento da formação literária do Brasil. Ora, foi exatamente este o caminho seguido por Mário António na sua tese de doutoramento, apenas lhe dando um toque muito pessoal, advindo de alguém que, por famílias e amizades, sabia também aquilo que se passara, que ele ouvira dizer e até, por essa mesma rede familiar extensa, em certos casos, ele pudera ler textos e documentos aos quais hoje não temos acesso. Quando vinha a propósito e já tinha consigo a informação, inseria-a, sem preocupação também de ser exaustivo ou erudito. As referências históricas e documentais aparecem, geralmente, como ícones de uma situação e também de um gosto de época de que nos dá notícia e que interpreta localizando-o no processo histórico de diferenciação que nos conduziria à primeira geração assumidamente independentista. O seu juízo crítico, entretanto, vai esfriando possíveis entusiasmos políticos, reconhecendo as limitações dos resultados estéticos alcançados e os textos ou aspetos em que, ao menos por momentos, os autores foram além delas.

Tanto quanto Antonio Candido, Mário António conhecia os primórdios da implantação da escrita e os primeiros sinais de uma produção literária que, entre nós, por coincidência, remontava ao princípio do século XVII, quando não ao final do anterior. Ele percebe-Ihes a função, lamentando embora que, no nosso caso, a incúria e a falta de condições não tenham permitido perpetuar a documentação comprovativa de uma atividade preliminar. A sua interpretação desses primeiros sinais vai no sentido da de Antonio Candido quando este afirma, no prefácio à segunda edição: "no sentido amplo, houve literatura entre nós desde o século XVI; ralas e esparsas manifestações sem ressonância, mas que estabelecem um começo e marcam posições para o futuro." Esta coincidência deve-se à própria história da formação da literatura angolana, à qual podemos aplicar, sem subtrair nem somar nada, esse longo período escrito por Antonio Candido e onde Mário António se reconheceu, com certeza.

É claro que houve diferenças, há sempre. Pode-se exemplificar com Gregório de Matos. Para o seu caso há em Angola uma correspondência muito mal conhecida: alguém de quem só sabemos o nome e o posto no exército, bem como que nascera por ali e teria sua veia de poeta - segundo Cadornega, aliás também lido por Mário António. Só Ihe conhecemos duas pequenas composições satíricas. 
Em compensação, proferiu-as mais de trinta anos antes de Gregório de Matos as copiar. Por outro lado, Angola teve, para a segunda metade do século XVII, os três volumes da História general das guerras angolanas (e em particular o III), de onde Gregório de Matos terá tirado as composições de que falei, copiando mais outra, que vem no final do vol. III e cuja autoria foi fixada por Francisco Topa (TOPA, 2013, 122-147). Em compensação, essa História, que me parece não ter paralelo no Brasil, ficou inédita quase até ao meio do século $X X$ e, portanto, não teve "ressonância", mesmo que no seu tempo constituísse um claro começo e marcasse alguma posição "para o futuro" - posição, aliás, retomada na segunda metade do século $X X$.

Uma vez passada em revisão a fase preliminar, também Mário António se guiou, como explicita o seu homónimo brasileiro, pelo critério da "continuidade da tradição" que se constituía e pela "interação dinâmica" no "triângulo "autor-obra-público»" (FLB, p. 16) articulado com a comunidade envolvente. Aqui, as balizas cronológicas começam a divergir, mas as fases de formação continuam sendo as mesmas, ou melhor: caracterizam-se pelas mesmas funções no decurso histórico. Também Mário António estudará a constituição do sistema (até patrológico) observando como ele vai pouco a pouco integrando-se e articulando-se com as aspirações da comunidade em que surge, logo nisso diferenciando-se da produção colonial (que persistiu no território por não ter havido independência de Angola no século XIX). A articulação sociopolítica da leitura literária, tão sublinhada como sua pelos intelectuais que formariam o MPLA, manteve-se no trabalho de Mário António, também nisso coincidente com o de Antonio Candido e o de seus antigos companheiros de Liceu.

Mário António estudou pormenorizadamente a "continuidade" entre os dois períodos ou momentos que estuda, cujo posicionamento no processo de formação da nossa literatura é equivalente ao que foram, para a brasileira, o período arcádico e o romântico. No caso angolano, o primeiro período no final do século XIX e o segundo no começo do seguinte. $\mathrm{Na}$ "passagem de um século para outro", no capítulo "Novo século: esperanças e fracassos", ele encontrou "certos elementos da formação nacional (dado histórico-social)" que levaram "o escritor a escolher e tratar de maneira determinada alguns temas literários (dado estético)" (CANDIDO, 2000, p. 16). Mostrou Mário António, no capítulo referido, a continuidade que firmava uma tradição, quer alicerçada em interações histórico-sociais e políticas, quer nas identificações estéticas e seu histórico no triângulo 
autor-texto-leitor. Para o último caso, realça Mário António o facto de os Ensaios literários do princípio do século XX republicarem o poema "Negra!" de Cordeiro da Matta, incluído nos Delírios (MATTA, 1889) e o de $O$ Angolense republicar as Scenas d'África de Pedro Félix Machado (MACHADO, 1891). "Negra!" representaria o testemunho romântico-africano (para usar os termos de Mário António) face ao avanço do racismo colonialista, com laivos de positivismo e de evolucionismo, mal mastigado por Oliveira Martins. Scenas d'África representaria o mesmo cariz testemunhal, mas agora através da tentativa de romance realista (para usar os termos de Mário António e de Nelson Pestana), que se tornará num cânone dominante até ao fim do século XX (refiro-me ao realismo literário, sempre testemunhal em Angola).

Tal dominância constitui uma outra coincidência com parte significativa da vida brasileira, justamente por essa característica, apontada por Antonio Candido e bem conhecida de Mário António, de ambas as literaturas estarem marcadas pelo "compromisso com a vida nacional" (CANDIDO, 2000, p. 18). Por esse compromisso e na linha do que antes fizera Cordeiro da Matta, no fim do século XIX, Mário António vai detetar a continuidade do protesto crioulo, ou angolense, desde a Demonstração de Joaquim António de Carvalho e Menezes (MENEZES, 1848) e da Memória que a antecedeu (MENEZES, 1834), até à Voz de Angola clamando no deserto (AAVV, 1901) - ou seja, nas duas fases da formação da literatura angolana como sistema.

Em um capítulo fundamental e que se autonomizou (o primeiro: "Literatura como sistema"), Candido resume a obra: "este livro procura estudar a formação da literatura brasileira como síntese de tendências universalistas e particularistas". Não sei de qualquer outra literatura que se possa estudar fora desse propósito, ou ignorando esse cariz fundamental de toda a arte literária. Porém, em vários momentos da história crítica angolana, houve tentativas de excluir das respetivas artes e literaturas, mesmo as urbanas, todo e qualquer sinal de "tendências universalistas". Objetivos desse tipo sempre se goram mas, enquanto persistem, suas tentativas obnubilam a dinâmica, a riqueza e a complexidade de uma literatura constantemente negociada entre oraturas várias e escrituras de origem diversa, cada uma reclamando o seu poder simbólico. Mário António sobreviveu e reagiu a um desses momentos de retração face ao universalismo, de onde a importância de ter seguido a pista lançada por Antonio Candido e ter 
buscado uma leitura atenta, simultaneamente, ao desenrolar da 'literatura mundial' e às dinâmicas que regionalizaram o processo no território hoje angolano.

Olhando para a literatura angolana como crioula, Mário António estudará a sua formação, precisamente, "como síntese de tendências universalistas e particularistas". Em virtude da situação colonial sofrida até 1975, ele acentuava, como os nacionalistas da sua geração e da seguinte, as condicionantes particulares dessa produção, para resgatá-la de uma imersão amorfa na 'literatura portuguesa', por via da literatura colonial portuguesa.

Tais condicionantes se prendiam, porém, a aspetos histórico-sociais. A componente literária, nesse período de formação de um sistema literário localizado, tem uma relação envergonhada com as tradições, que Antonio Candido igualmente compreenderia. Mesmo quando as recolhe (caso de Cordeiro da Matta), não escreve poesia nem contos seguindo as suas regras de composição. Portanto, a síntese encontrada por Mário António, na esteira de Antonio Candido e das teorias da crioulidade, vai levá-lo a compreender, por exemplo, a lírica de Maia Ferreira em função da escola ultrarromântica e de práticas sociais glocais, como a de colocar poemas em álbuns. Ele caracteriza esse ultrarromantismo de salão como poesia ramos-de-flores-para-os-amigos, a partir daí explicando parte da lírica de Maia Ferreira. Vai notar, também, no mesmo poeta, uma agilidade métrica e rítmica acentuada, se comparada com a da maioria dos discípulos de António Feliciano de Castilho. Compreende a posição de Maia Ferreira, a partir daí e da consideração do momento político-social, com uma visão semelhante àquela com que Antonio Candido olhou para os Árcades: "fizeram [...] uma poesia inteligível aos homens de cultura [...] que eram então os destinatários das obras."

Com isso possibilitou Maia Ferreira que "a literatura funcionasse" (FLB, idem) em Angola, começando a insuflar-lhe alguma cor local, acentuada mais tarde por Cordeiro da Matta, não a despeito do cânone globalizado mas, precisamente, por solicitação e expetativa dentro desse cânone. Mário António percebeu isto em Angola.

No seguimento, veio flagrar a lírica de Cordeiro da Matta no momento posterior da formação da sua comunidade literária e nacional, sobre a qual ainda pairava uma grande sombra ultrarromântica, já misturada com tentativas de superação, principalmente por aproximações à escola realista. Esse momento se caracterizará, também, pela mais intensa ligação às oraturas locais, sobretudo 
em torno de Luanda e principalmente na obra de Cordeiro da Matta. Mário António mostrará, sem deixar de perceber a componente universalista do poeta negro do rio Cuanza, como a sua abordagem etnográfica sobre a oratura local e o tratamento literário da mulher africana se inseriram no processo de constituição e reclamação de um espaço cultural e político próprio. Ela sustentará o projeto crioulo sem deixar de participar no esforço intelectual de época, o da atenção às expressões populares tratadas enquanto certificados identitários. É mesmo por essa via que ele encontra a continuidade, explicitamente estabelecida, entre os protestos jornalísticos do princípio do século XX e a produção literária do último quartel do século XIX, do que ele chamava a geração de 1880 . Em ambos os casos, Mário António estuda a "«tomada de consciência» dos autores quanto ao seu papel, e à intenção mais ou menos declarada de escrever para a sua terra, mesmo quando não a descreviam." (CANDIDO, 2000, p. 26) Também entre angolenses se notará esse "elemento ambíguo de pragmatismo" que pode levar escritores e estudiosos a ter de, em certos momentos, extravasar do campo literário, "abandonar o terreno específico das belas-letras."

Os escritores angolanos do princípio do século fizeram isso e o seu estudioso, inaugurando uma linha de leitura seguida por muitos que o criticavam, passou à consideração do papel das polémicas políticas e jornalísticas na formação da literatura angolana, como se de literatura se tratasse também. Daí que Mário António sublinhe a "fidelidade documentária" na formação local de uma tradição literária, "fidelidade" referida por Antonio Candido para o período formativo que estuda (CANDIDO, 2000, p. 27). Antonio Candido fala em "documentária ou sentimental", Mário António, condicionado pelo seu objeto de estudo, fala no "testemunho" - palavra e radical que se repetem constantemente na sua tese de doutoramento e em particular no capítulo sobre o começo do século XX (período equivalente, nestes aspetos, ao começo do século XIX na literatura brasileira).

Dessa forma se identifica, o ensaísta de Maquela do Zombo, em três aspetos com as propostas de Antonio Candido em Formação da Literatura Brasileira:

1. "a formação de continuidade literária" pelo "compromisso com a vida nacional" (no nosso caso e nessa época, a vida angolense) e a definição funcional da literatura "como eminentemente interessada" (CANDIDO, 2000, p. 17); 
2. o da conjugação do juízo estético sobre as obras com o levantamento das articulações sociais e políticas delas e dos autores, inseridos conscientemente no processo histórico;

3. o da verificação de tendências universalistas (sobretudo estéticas) e particularistas (as histórico-sociais).

Assim, foi na esteira de Antonio Candido, permanecendo fiel aos princípios que perfilaram sua personalidade cultural nos tempos do Liceu, que Mário António estudou a formação da literatura angolana como a história dos angolenses, ou crioulos de Angola, "no desejo de ter uma literatura" própria (CANDIDO, 2000, p. 25), que se constituísse em sistema nacional. O trabalho de Antonio Candido, por mais que ele o não referisse, formatou para Mário António o tipo de crítica expectável a partir da configuração do seu pensamento comprometido e mensageiro, mas também de crítico literário autónomo.

\section{Referências}

ANDRADE, Mário Coelho Pinto de. Origens do nacionalismo africano: continuidade e ruptura dos movimentos unitários emergentes da luta contra a dominação colonial portuguesa: 1911-1961. Lisboa: D. Quixote, 1997.

CANDIDO, Antonio. Formação da literatura brasileira: momentos decisivos. 9.a ed. Belo Horizonte: Itatiaia, 2000. V. I 1750-1836 (Col. Reconquista do Brasil. 2.a série; v. 177).

KAJIBANGA, Victor. A questão da ruptura e da continuidade (proto)nacionalista na obra de Mário Pinto de Andrade: uma contribuição ao estudo sociológico do programa de pesquisa do 2 o volume da obra Origens do Nacionalismo Africano. África / CEA-USP, São Paulo, n.o 20-21, pp. 285-303, 1998. Disponível em: http://www.revistas.usp.br/africa/ article/view/75259. Acesso em: 27 out 2018.

OLIVEIRA, Mário António Fernandes de. A formação da literatura angolana: 1851-1950. Lisboa: IN-CM, 2005. (Col. Escritores dos Países de Língua Portuguesa, 13).

TOPA, Francisco. Entre a terra de gente oprimida e a terra de gente tostada: Luís Félix da Cruz e o primeiro poema angolano. Literatura em debate / URI, Frederico Westfalen, v. 7, n. 13, p. 122-147, 2013. 